\title{
Psychometric Instrument Reliability
}

National Cancer Institute

\section{Source}

National Cancer Institute. Psychometric Instrument Reliability. NCI Thesaurus. Code C142655.

The extent to which the administration of a psychometric instrument and the data collected from that administration is accurate, repeatable, and sensitive. 